\title{
Sülfonamit İçeren Maleamik Asit Türevi ile 2-Aminopiridinin Proton Transfer Tuzu ve Co(II) ve Cu(II) Komplekslerinin Sentezi, Karakterizasyonu ve Karbonik Anhidraz İzoenzimleri Üzerindeki İnhibisyon Özelliklerinin İncelenmesi
}

\author{
Halil İlkimen ${ }^{1 *}$, Cengiz Yenikaya ${ }^{1}$, Metin Bülbül ${ }^{2}$, Gözde İmdat ${ }^{3}$ \\ ${ }^{1}$ Dumlupınar Üniversitesi, Fen-Edebiyat Fakültesi Kimya Bölümü, 43100, Kütahya, TÜRKİYE, +90 2742652031 , \\ halil.ilkimen@dpu.edu.tr. \\ 2Dumlupınar Üniversitesi, Fen-Edebiyat Fakültesi Biyokimya Bölümü, 43100, Kütahya, TÜRKIYE, +90 2742652031 \\ ${ }^{3}$ Dumlupınar Üniversitesi, Fen Bilimleri Enstitüsü, 43100, Kütahya, TÜRKİYE. \\ *Iletişimden sorumlu yazar / Corresponding author \\ Geliş / Received: 27 Haziran (June) 2016 \\ Kabul / Accepted: 7 Ocak (January) 2016 \\ DOI: $10.18466 /$ cbayarfbe.302655
}

\begin{abstract}
Özet
Bu çalışmada, ilk olarak 3-aminobenzensülfonilamit (abs) ile maleik anhidritin (mal) tepkimesinden (E)-4-okso-4-(3sülfamoyilfenil)amino)büt-2-enoik asit (Hmabsmal) bileşiği sentezlenmiştir. Daha sonra Hmabsmal bileşiği ile 2aminopiridinin (ap) proton transfer tuzu (1) hazırlanmıştır. Bu maddelerin değişik yöntemlerle $\mathrm{Co}$ (II) (2) ve $\mathrm{Cu}$ (II) (3 ve 4) geçiş metal kompleksleri sentezlenmiştir. Proton transfer tuzunun yapisı elementel analiz, ${ }^{1} \mathrm{H}-\mathrm{NMR},{ }^{13} \mathrm{C}-\mathrm{NMR}$, FT-IR, UV-Vis metotları ile aydınlatılmıştır. Amorf halde elde edilen geçiş metal komplekslerinin yapıları ise elementel analiz, ICP-OES, FT-IR, UV-Vis, termal analiz, manyetik duyarlılık ve molar iletkenlik sonuçları dikkate alınarak önerilmiştir. Ayrıca, sentezlenen maddelerin insan eritrosit hCA I ve hCA II izoenzimleri üzerindeki inhibisyon etkilerini belirlemek üzere in vitro çalışmalar yapılmıştır. Yeni sentezlenen maddelerin izoenzimlerin esteraz aktivitesini inhibe ettiği, hidrataz aktivitesini ise sadece 3 bileşiğinin inhibe ettiği tespit edilmiştir. Bu maddelerin inhibisyon değerlerinin kontrol bileşiği asetazolamid (AAZ) değerleri ile kıyaslanabilir büyüklükte olduğu tespit edilmiştir.
\end{abstract}

Anahtar Kelimeler - Sülfonamit Bileşikleri, 2-Aminopiridin, Proton Transfer Tuzu, Metal Kompleksleri, Karbonik Anhidraz İnhibisyonu.

\section{Synthesis and Characterization of Proton Transfer Salt Between Maleamic Acid Derivative Including Sulfonamide Moiety and 2-aminopyridine and Preparation of Their Co(II) and $\mathrm{Cu}$ (II) Complexes and Investigation of Inhibition Properties on Carbonic Anhydrase Isoenzymes}

\footnotetext{
Abstract

In this study, firstly (E)-4-oxo-4-(3-sulfamoylphenylamino)but-2-enoic acid (Hmabsmal) has been synthesized from the reaction between 3-aminobenzenesulfonamide (abs) and maleic anhydride (mal) and secondly, proton transfer salt has been prepared from 2-aminopyridine (ap) and Hmabsmal. Transition metal complexes of these substances, $\mathrm{Co}(\mathrm{II})$ (2) and $\mathrm{Cu}(\mathrm{II})$ (3 and 4), have been synthesized by different methods. The structure of proton transfer compounds have been proposed by using elemantal analysis, ${ }^{1} \mathrm{H}-\mathrm{NMR},{ }^{13} \mathrm{C}-\mathrm{NMR}$, UV-Vis techniques. The structure of amorphous metal complexes have been proposed by using elemantal analysis, ICP-OES, FT-IR, UV-Vis, thermal analysis, magnetic susceptibility and molar conductivity techniques. In addition, in vitro studies have been performed to determine the inhibition effects of synthesized compounds on human erythrocyte hCA I and hCA II isoenzymes. It
} 
has been observed that synthesized compounds have affected esterase activities of hCA I and hCA II. But only compound 3 has inhibiton effect on the hydratase activities on the isozymes. Also the inhibition values of these compounds are comparable with the inhibition values of control compound acetazolamide (AAZ).

Keywords - Sulfonamide Compounds, 2-Aminopyridine, Proton Transfer Salt, Metal Complexes, Carbonic

Anhydrase Inhibition.

\section{Giris}

Proton transfer tepkimeleri fizik, kimya ve biyokimyada temel işlemlerden olan suyun öziyonlaşması, asit-baz nötralizasyon tepkimesi ve enzim katalizi gibi reaksiyonlarda önemli bir anahtar görevi görür [1]. Proton transfer tepkimelerinde asitin protonu, bazın ortaklaşmamış elektronu tarafından transfer edilir. Böylece oluşan (+) ve (-) yüklerin bir araya gelerek oluşturdukları tuzlara proton transfer tuzları denir. Proton transfer tuzlarınin, metal iyonları ile oluşturdukları metal kompleksleri genellikle suda çözünebilen iyonik bileşiklerdir [2].

Glokom; optik sinir başının dönüşümsüz hasarına neden olan yüksek göz içi basıncı ile karakterize edilen, görme fonksiyonunun kademeli olarak azalmasına bağlı körlükle sonuçlanan kronik, dejeneratif bir göz rahatsızlığıdır [3]. Glokom tedavisi için yapılan çalışmalar prostaglandin analoglarının, beta blockerların, adrenerjik ajanların, kolinerjik ilaçların, osmotik ilaçların ve karbonik anhidraz inhibitörlerinin bu hastalığın tedavisinde etkili olduklarını göstermiştir. Karbonik anhidraz inhibitörleri olarak ise günümüzde daha çok sülfonamit türevleri kullanılmaktadır [4].

$\mathrm{Bu}$ çalışmanın asidik bileşeni olan, sülfonamit grubu içeren bileşiklerin, antimikrobiyal, antidiyabetik, antienflamatuar, enzim inhibitörü, enfeksiyon tedavisi, ağrı kesici, menisküs ve romatizma tedavisi gibi biyolojik özellikleri de bilinmektedir. [5-12].

Bu çalışmanın bazik bileşeni olan 2-aminopiridinler inorganik ve organometalik uygulamalarda çok dişli ligandlar olarak kullanılmaktadır [13-15]. 2-Aminopiridinler, çoğunlukla halkanın azot atomu yoluyla metal iyonlarına tek dişli ligant [1619] olarak bağlansa da; bazı çalışmalarda amino grubunun da yer aldığ $[20,21]$.
$\mathrm{Bu}$ çalışmada önce 3-aminobenzensülfonamit (mabs) ile maleik anhidritin (mal) tepkimesi sonucunda sülfonamit grubu içeren amit bileşiği literatürdeki gibi sentezlenmiştir [(E)-4-okso-4-(3sülfamoyilfenil) amino)büt-2-enoik asit, Hmabsmal] [22]. Daha sonra 2-aminopiridin (ap) ile Hmabsmal tepkimesinden proton transfer tuzu bileşiği $\left[(\mathrm{Hap})^{+}(\right.$mabsmal)-, 2-aminopridinyum (E)-4-okso-4(3-sülfamoyilfenil) amino)büt-2-enoat, hazırlanmıştır. Bu tuzun $\mathrm{Co}(\mathrm{II})$ ve $\mathrm{Cu}(\mathrm{II})$ ile verdiği komplekslerin yapıları (2-4) aydınlatılmaya çalışılmıştır. Ayrıca, sentezlenen maddelerin insan eritrosit karbonik anhidraz (hCA) I ve II izoenzimleri üzerindeki inhibisyon etkilerini belirlemek üzere in vitro çalışmalar yapılmıştır.

\section{Materyal ve Metot}

\subsubsection{Kullanılan Kimyasal Maddeler}

Bu çalışmada kullanılan kimyasal maddeler Sigma Aldrich firmasından temin edilmiştir.

\subsubsection{Analizlerde Kullanılan Cihazlar}

NMR Cihazl; Bruker DPX FT NMR (500 MHz), Elementel Analiz Cihazı; Leco CHNS 932, ICP-OES Cihazl; Perkin Elmer 4300 Optima, İnfrared Spektrometresi; Bruker Optics Vertex 70, TG-DTA cihazi; Pelkin Elmer, SII Exstar 6000 TG/DTA 6300, UV-Vis cihaz1; Shimadzu UV-2550 Spektrometresi, Manyetik Duyarlılık Cihazı; Sherwood Scientific Magway MSB MK1, Molar İletkenlik Cihazı; WTW Cond 315i/SET Model.

\subsection{Metot}

\subsubsection{Hmabsmal Sentezi}

5 mmol (0.86 g) 3-Aminobenzensülfonamit bir balonda $10 \mathrm{~mL}$ kuru asetonda çözüldü. $5 \mathrm{mmol}$ (0.49 g) maleik anhidrit katı olarak çözelti üzerine ilave edildi. Oda koşullarında 2 saat karıştırma işleminden sonra reaksiyon ortamında çöken katı 
süzüldü, kuru asetonla yıkandı ve kurutuldu (Şekil 2. 1). Elde edilen bileşiğin bazı fiziksel özellikleri Tablo 1'de verilmiştir.

\subsubsection{Proton Transfer Tuzunun Sentezi (1)}

10 mmol Hmabsmal bileşiği (2.70 g) bir balon içerisinde $20 \mathrm{~mL}$ saf etanolde çözüldü. $10 \mathrm{mmol}$ ap bileşiği (0.941 g) ayrı bir balon içerisinde $20 \mathrm{~mL}$ saf etanolde çözüldü. Oda koşullarında ap çözeltisi, Hmabsmal çözeltisinin üzerine damla damla ilave edildi. 24 saatlik bir karıştırma işleminden sonra reaksiyon ortamında çöken beyaz renkli proton transfer tuzu (1) süzüldü, saf etanol ile yıkandı ve kurutuldu (Şekil 2. 1). Elde edilen tuzun bazı fiziksel özellikleri Tablo 1'de verilmiştir.

\subsubsection{Metal Komplekslerinin Sentezi}

\subsubsection{Yöntem 1}

Proton transfer tuzundan $1 \mathrm{mmol}(0.364 \mathrm{~g})$ alınarak $10 \mathrm{~mL}$ su:etanolde (1:1) çözüldü. Üzerine $0.5 \mathrm{mmol}$ metal tuzunun $\left[0.229 \mathrm{~g} \mathrm{Co}\left(\mathrm{CH}_{3} \mathrm{COO}\right)_{2} .4 \mathrm{H}_{2} \mathrm{O}\right.$ (2) veya $0.099 \mathrm{~g} \mathrm{Cu}\left(\mathrm{CH}_{3} \mathrm{COO}\right)_{2} . \mathrm{H}_{2} \mathrm{O}$ (3)] $10 \mathrm{~mL}$ sudaki çözeltisi ilave edildi ve 72 saat oda sıcaklığında karıştırıldıktan sonra kristallenmeye bırakıldı. Çözelti ortamında çöken metal kompleksleri süzüldü ve kurutuldu (Şekil 2. 1). Elde edilen kompleks bileşiklerin bazı fiziksel özellikleri Tablo 1 'de verilmiştir.

\subsubsection{Yöntem 2}

$1 \mathrm{mmol}$ Hmabsmal (2.70 g), $1 \mathrm{mmol}$ ap (0.094 g) ve $0.5 \mathrm{mmol}$ metal(II) tuzu $[0.125 \mathrm{~g}$ $\mathrm{Co}\left(\mathrm{CH}_{3} \mathrm{COO}\right)_{2} .4 \mathrm{H}_{2} \mathrm{O} \quad$ (2) veya $0.099 \quad \mathrm{~g}$ $\left.\mathrm{Cu}\left(\mathrm{CH}_{3} \mathrm{COO}\right)_{2} \cdot \mathrm{H}_{2} \mathrm{O}(4)\right]$ alınarak $25 \mathrm{~mL}$ su:etanolde (1:1) çözüldü. 72 saat oda sıcaklığında karıştrıldıktan sonra kristallenmeye birakıldı. Çözelti ortamında çöken metal kompleksleri süzüldü ve kurutuldu (Şekil 2. 1). Yapılan analizler sonucunda $\mathrm{Co}$ (II) kompleksinin her iki yöntemle de aynı ürün şeklinde (2) elde edildiği tespit edilmiştir. Elde edilen kompleks bileşiklerin bazı fiziksel özellikleri Tablo 1'de verilmiştir.

Tablo 1. Sentezlenen bileşiklerin bazı fiziksel özellikleri

\begin{tabular}{clll}
\hline Bileşik & Renk & $\begin{array}{l}\text { Mol } \\
\text { Kütlesi }^{*}\end{array}$ & $\begin{array}{l}\text { Verim } \\
\text { (\%) }\end{array}$ \\
\hline Hmabsmal & Beyaz & 270.26 & 90 \\
$\mathbf{1}$ & Beyaz & 364.38 & 85 \\
$\mathbf{2}$ & Pembe & 551.44 & 70 \\
$\mathbf{3}$ & Yeşil & 541.48 & 70 \\
$\mathbf{4}$ & Yeşil & 845.34 & 75 \\
\hline
\end{tabular}

*Tahmini molekül ağırlığı $(\mathrm{g} / \mathrm{mol})$

\subsubsection{In vitro İnhibisyon Çalışmaları}

2.2.5.1 Sentezlenen bileşiklerin hCA I ve hCA II izoenzimlerinin hidrataz ve esteraz aktivitesi üzerindeki inhibisyon etkilerinin incelenmesi ve IC ${ }_{50}$ değerlerinin belirlenmesi

Yeni sentezlenen bileşiklerin glokom hastalığ tedavisi için klinikte lokal olarak kullanılan miktar olan \%1'lik çözeltileri hazırlanarak insan karbonik anhidraz I ve II izoenzimlerinin hidrataz ve esteraz aktiviteleri üzerine inhibisyon etkileri incelenmiştir. İnsan eritrositlerinden saflaştırılan hCA I ve hCA II izoenzimleri için beş farklı uygun inhibitör konsantrasyonunda hidrataz ve esteraz aktivite ölçümleri yapılmıştır $[23,24]$. İnhibisyon etkisi olan bileşiklerin \%Aktivite-[I] grafikleri çizilerek $\mathrm{IC}_{50}$ değerleri hesaplanmıştır. 


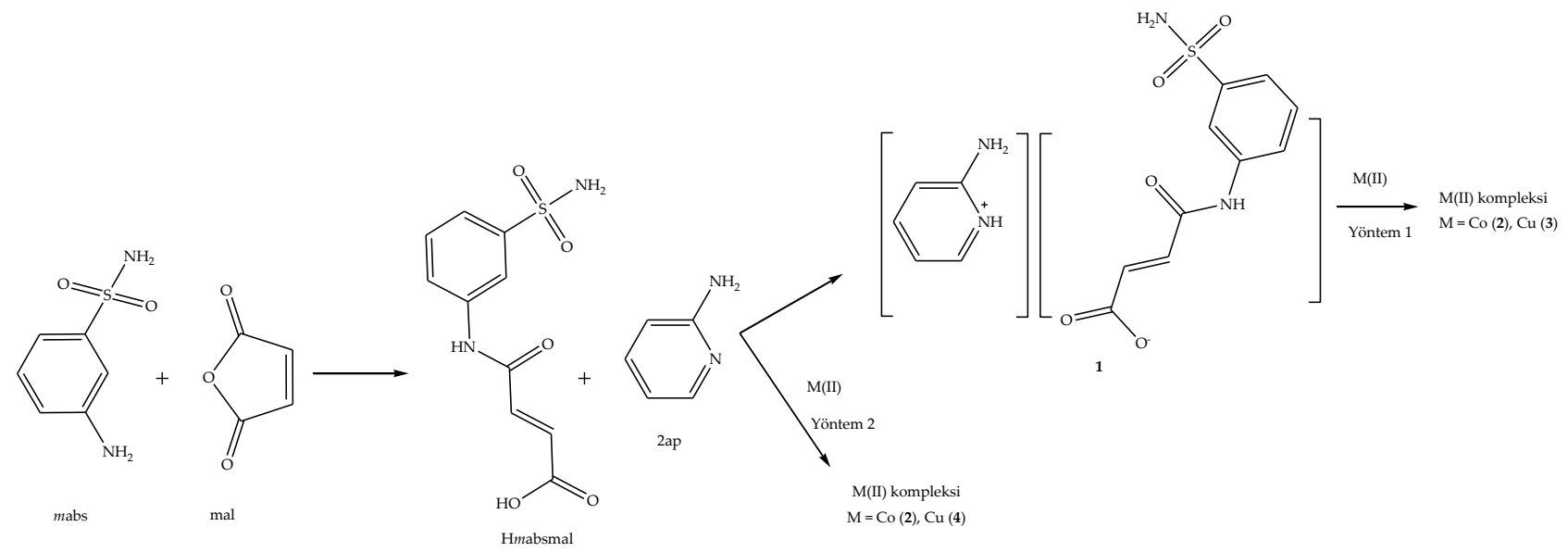

Şekil 2. 1 Proton transfer tuzu ve metal komplekslerinin sentezi

\subsubsection{2 İnhibitörlerin inhibisyon sabiti $\left(K_{\mathrm{i}}\right)$ değerlerinin hesaplanması}

$K_{\mathrm{i}}$ değerlerini bulmak için eritrosit hCA I ve hCA II izoenzimlerinin esteraz aktiviteleri üzerinde yeni sentezlenen bileşiklerin inhibisyon etkileri; enzim üzerine ilave edildiği deneylerde, inhibitörlü ve inhibitörsüz olarak beş farklı substrat konsantrasyonu için esteraz aktivite ölçümleri yapılarak belirlenmiştir $[25,26]$.

Her bir inhibitörün, hCA I ve hCA II izoenzimleri için ayrı ayrı Lineweaver-Burk grafikleri çizilmiştir. $\mathrm{Bu}$ grafiklerden elde edilen denklemlerden $K_{i}$ değerleri hesaplanmiştır.

\section{Sonuçlar ve Tartışma}

\subsection{Elementel Analiz ve ICP-OES sonuçları}

Sentezlenen başlangıç maddesi, proton tuzu ve metal komplekslerinin elementel analiz ve komplekslerin ICP-OES sonuçları Tablo 2'de verilmiştir. Deneysel olarak elde edilen değerlerin, hem teorik elementel analiz değerleri ile hem de diğer spektroskopik çalışmalar sonucu ortaya konulan yapılar ile uyum içinde olduğu gözlenmiştir.

$\mathrm{Bu}$ çalışmada hazırlanan tuzun asit ve baz oranları elementel analiz sonuçlarına göre belirlenmiştir. Buna göre hazırlanan proton transfer tuzundaki asit ve baz birleşme oranları 1:1 olarak bulunmuştur. Elementel analiz ve ICP-OES sonuçlarına göre metal komplekslerinde Metal:Asit:Baz oranının; 2 kompleksi için 1:1:2, 3 kompleksi için 2:1:1 ve 4 kompleksi için 1:2:2 olduğu görülmektedir.

Tablo 2. Sentezlenen bileşiklerin elementel analiz ve ICP-OES sonuçları

\begin{tabular}{clccccc}
\hline Bileşik & Kapalı formülü & \multicolumn{5}{c}{ \% Deneysel(\% Teorik) } \\
\hline & & \multicolumn{1}{c}{$\mathbf{C}$} & $\mathbf{H}$ & $\mathbf{N}$ & $\mathbf{S}$ & $\mathbf{M}$ \\
\hline $\mathrm{H} m$ mabsmal & $\mathrm{C}_{10} \mathrm{H}_{10} \mathrm{~N}_{2} \mathrm{O}_{5} \mathrm{~S}$ & $44.50(44.44)$ & $3.75(3.73)$ & $10.40(10.37)$ & $11.85(11.86)$ & - \\
$\mathbf{1}$ & $\mathrm{C}_{15} \mathrm{H}_{16} \mathrm{~N}_{4} \mathrm{O}_{5} \mathrm{~S}$ & $49.45(49.44)$ & $4.35(4.43)$ & $15.40(15.38)$ & $8.85(8.80)$ & - \\
$\mathbf{2}$ & $\mathrm{C}_{20} \mathrm{H}_{24} \mathrm{~N}_{3} \mathrm{O}_{7} \mathrm{SCo}$ & $43.50(43.56)$ & $4.25(4.39)$ & $15.20(15.24)$ & $5.80(5.81)$ & $10.65(10.69)$ \\
$\mathbf{3}$ & $\mathrm{C}_{15} \mathrm{H}_{18} \mathrm{~N}_{4} \mathrm{O}_{8} \mathrm{SCu}_{2}$ & $33.35(33.27)$ & $3.35(3.35)$ & $10.30(10.35)$ & $5.85(5.91)$ & $(23.40)(23.47)$ \\
$\mathbf{4}$ & $\mathrm{C}_{30} \mathrm{H}_{37} \mathrm{~N}_{8} \mathrm{O}_{13} \mathrm{~S}_{2} \mathrm{Cu}$ & $42.57(42.62)$ & $4.60(4.41)$ & $13.25(13.26)$ & $7.60(7.59)$ & $(7.45)(7.52)$ \\
\hline
\end{tabular}

\subsection{NMR Spektrumu Sonuçları}

\subsubsection{Hmabsmal Bileşiğinin NMR Spektrumları}

Sentezlenen Hmabsmal bileşiğinin (Şekil 4. 1) DMSO-d 6 içerisinde alınan ${ }^{1} \mathrm{H}-\mathrm{NMR}$ ve ${ }^{13} \mathrm{C}-\mathrm{NMR}$ spektrum değerleri Tablo 3'de, spektrumları Ekler 1-3'de verilmiştir.

Hmabsmal bileşiğinin ${ }^{1} \mathrm{H}-\mathrm{NMR}$ spektrumunda (Ekler 1 ve 2, Tablo 3); 6.48 ppm $\left(\mathrm{H}^{3},{ }^{3} \mathrm{~J}_{\mathrm{H} 3-\mathrm{H} 4}=11.98\right.$ $\mathrm{Hz})$ ve $6.34 \mathrm{ppm}$ 'de $\left(\mathrm{H}^{4},{ }^{3} \mathrm{~J} \mathrm{H} 4-\mathrm{H} 3=11.96 \mathrm{~Hz}\right)$ gözlenen 
$1 \mathrm{H}^{\prime}$ lık doublet pikler alken protonlarından $(-\mathrm{CH}=\mathrm{CH}-)$ kaynaklanan piklerdir. Bu hidrojenlerin $\mathrm{Hz}$ değerleri yaklaşık 12 olması yapının trans pozisyonda olduğunu göstermektedir [27]. 7.55 ppm'de gözlenen $2 \mathrm{H}^{\prime}$ lik triplet (doublet + triplet) pik $\left(\mathrm{H}^{8},{ }^{3} \mathrm{~J}_{\mathrm{H} 8-\mathrm{H} 9}=7.26 \mathrm{~Hz}\right.$ ve $\left.\mathrm{H}^{9},{ }^{3}{ }_{\mathrm{H}} \mathrm{H}-\mathrm{H} 8,10=7.72 \mathrm{~Hz}\right)$ ve 7.75 ppm'de gözlenen $1 \mathrm{H}^{\prime}$ lik doublet pik $\left(\mathrm{H}^{10}\right)$ benzen halkasındaki hidrojenlerden kaynaklanmaktadır. Yapida bulunan $-\mathrm{SO}_{2} \mathrm{NH}_{2}$ hidrojenleri $\left(\mathrm{H}^{14}\right)$ ve amit hidrojeni $\left(\mathrm{H}^{6}\right)$ sirayla 7.39 ppm'de 2H'lik singlet ve 10.60 ppm'de $1 \mathrm{H}^{\prime}$ lik singlet pik olarak gözlenmiştir. Yapıdaki karboksil grubunda bulunan proton $\left(\mathrm{H}^{1}\right)$ ise 12.95 ppm'de $1 \mathrm{H}^{\prime}$ lık singlet olarak gözlenmiştir. Örnek çözeltisi üzerine $\mathrm{D}_{2} \mathrm{O}$ ilavesinden sonra çekilen ${ }^{1} \mathrm{H}-\mathrm{NMR}$ spekturumunda (Ek 2); $\mathrm{H}^{1}, \mathrm{H}^{6}$ ve $\mathrm{H}^{12}$ hidrojenleri gözlenmemiştir.

Hmabsmal bileşiğinin ${ }^{13} \mathrm{C}-\mathrm{NMR}$ spekturumunda (Ek 3, Tablo 3); 164 ppm'de gözlenen pik karboksil grubu karbonuna $\left(-\mathrm{C}^{2} \mathrm{OOH}\right), 167$ ppm'de gözlenen pik ise amit grubunun karbon atomuna $\left(\mathrm{C}^{5}\right)$ aittir. Sülfamoyil grubunun bağlı olduğu karbon ($\mathrm{C}^{11} \mathrm{SO}_{2} \mathrm{NH}_{2}$ ) piki 145 ppm'de ve -NH grubuna bağl1 karbon atomunun $\left(\mathrm{C}^{7}\right)$ piki ise 140 ppm'de gözlenmiştir. Aromatik bölgede bulunan diğer karbon atomlarınin $\left(\mathrm{C}^{8}, \mathrm{C}^{9}, \mathrm{C}^{10}\right.$ ve $\left.\mathrm{C}^{12}\right)$ pikleri ise sirasıyla 130, 121, 117 ve 123 ppm'de gözlenmiştir. Alken karbon atomları sırasıyla $131\left(\mathrm{C}^{3}\right)$ ve $132\left(\mathrm{C}^{4}\right)$ ppm'de gözlenmiştir.

\subsection{2 (1) Bileşiğinin NMR Spektrumları}

Sentezlenen proton transfer tuzu (1) bileşiğinin (Şekil 4. 2) DMSO-d6 içerisinde alınan ${ }^{1} \mathrm{H}-\mathrm{NMR}$ ve ${ }^{13} \mathrm{C}-\mathrm{NMR}$ spektrum değerleri Tablo 3'de, spektrumları Ekler 4-6'da verilmiştir.

Proton transfer tuzu (1) bileşiğinin ${ }^{1} \mathrm{H}-\mathrm{NMR}$ spektrumunda (Ekler 4 ve 5, Tablo 3); $6.40 \mathrm{ppm}\left(\mathrm{H}^{3}\right.$, $\left.{ }^{3} \mathrm{JH}_{\mathrm{H}-\mathrm{H} 4}=11.61 \mathrm{~Hz}\right)$ ve $6.35 \mathrm{ppm}$ 'de $\left(\mathrm{H}^{4},{ }^{3}{ }^{\mathrm{H}} 4-\mathrm{H} 3=11.36\right.$ $\mathrm{Hz})$ gözlenen $1 \mathrm{H}^{\prime} \mathrm{l} \mathrm{k}$ doublet pikler alken protonlarından $(-\mathrm{CH}=\mathrm{CH}-)$ kaynaklanan piklerdir. $\mathrm{Bu}$ hidrojenlerin $\mathrm{Hz}$ değerleri yaklaşık 12 olması yapının trans pozisyonda olduğunu göstermektedir [27]. 7.40 ppm'de gözlenen $3 \mathrm{H}^{\prime}$ lik doublet (doublet + triplet) pik $\left[\mathrm{H}^{8}, \mathrm{H}^{9}\right.$ ve $\left.\mathrm{H}^{10},\left({ }^{3} \mathrm{~J}=18.92 \mathrm{~Hz}\right)\right]$ mabsmal grubundaki benzen halkası hidrojenlerden kaynaklanmaktadır. Ap grubu hidrojenleri ise; 7.90 ppm'de $1 \mathrm{H}^{\prime}$ lik doublet-doublet beklenirken singlet $\left(\mathrm{H}^{15}\right), 6.50$ ppm'de $2 \mathrm{H}^{\prime}$ lik triplet-doublet beklenirken singlet $\left(\mathrm{H}^{16}\right.$ ve $\left.\mathrm{H}^{17}\right)$ ve ise 7.75 ppm'de $1 \mathrm{H}^{\prime}$ lik triplet-doublet beklenirken singlet $\left(\mathrm{H}^{18}\right)$ gözlenmiştir. Yapıda bulunan amit hidrojeni $\left(\mathrm{H}^{6}\right),-\mathrm{SO}_{2} \mathrm{NH}_{2}$ hidrojenleri $\left(\mathrm{H}^{14}\right)$ ve $-\mathrm{NH}_{2}$ $\left(\mathrm{H}^{21}\right)$ hidrojenleri sirayla 11.20 ppm'de $1 \mathrm{H}^{\prime} \mathrm{l} 1 \mathrm{k}$ singlet, 7.55 ppm'de $2 \mathrm{H}^{\prime}$ lık singlet ve 6.20 ppm'de $2 \mathrm{H}^{\prime}$ lik singlet pik olarak gözlenmiştir.

Tablo 3. Hmabsmal ve 1 bileşiğinin ${ }^{1} \mathrm{H}-\mathrm{NMR}$ ve ${ }^{13} \mathrm{C}-\mathrm{NMR}$ spektrumunun kimyasal kayma değerleri $\delta(\mathrm{ppm})$

\begin{tabular}{|c|c|c|c|c|c|c|c|}
\hline $\begin{array}{r}\mathrm{H}_{2} \mathrm{~N}^{-} \\
14\end{array}$ & $\overbrace{}^{8}$ & O & & {$\left[{ }^{21}\right.$} & 10 & $\mathrm{O}$ & \\
\hline $\mathrm{H}^{1}$ & $12.95(1 \mathrm{H} \mathrm{s})$ & $\mathrm{C}^{2}$ & 164 & $\mathrm{H}^{3}$ & $6.40(1 \mathrm{H}, \mathrm{d})\left[3 \mathrm{~J}_{\mathrm{H} 3-\mathrm{H} 4}=11.61 \mathrm{~Hz}\right]$ & $\mathrm{C}^{2}$ & 164 \\
\hline $\mathrm{H}^{3}$ & $6.48(1 \mathrm{H}, \mathrm{d})\left[{ }^{3} \mathrm{~J}_{\mathrm{H} 3-\mathrm{H} 4}=11.98 \mathrm{~Hz}\right]$ & $\mathrm{C}^{3}$ & 131 & $\mathrm{H}^{4}$ & $6.35(1 \mathrm{H}, \mathrm{d})\left[3 \mathrm{~J}_{\mathrm{H} 4-\mathrm{H} 3}=11.36 \mathrm{~Hz}\right]$ & $\mathrm{C}^{3}$ & 131 \\
\hline $\mathrm{H}^{4}$ & $6.34(1 \mathrm{H}, \mathrm{d})\left[{ }^{3} \mathrm{~J} \mathrm{H} 4-\mathrm{H} 3=11.96 \mathrm{~Hz}\right]$ & $\mathrm{C}^{4}$ & 132 & $\mathrm{H}^{6}$ & $11.20(1 \mathrm{H}, \mathrm{s})$ & $\mathrm{C}^{4}$ & 132 \\
\hline $\mathrm{H}^{6}$ & $10.60(1 \mathrm{H}, \mathrm{s})$ & $\mathrm{C}^{5}$ & 167 & $\mathrm{H}^{8}, \mathrm{H}^{9}, \mathrm{H}^{10}$ & $7.40(3 \mathrm{H}, \mathrm{d})[3 \mathrm{~J}=18.92 \mathrm{~Hz}]$ & $\mathrm{C}^{5}$ & 167 \\
\hline $\mathrm{H}^{8}$ & $7.55(1 \mathrm{H}, \mathrm{d})\left[3 \mathrm{~J}_{\mathrm{H} 8-\mathrm{H} 9}=7.26 \mathrm{~Hz}\right]$ & $\mathrm{C}^{7}$ & 140 & $\mathrm{H}^{12}$ & $8.25(1 \mathrm{H}, \mathrm{s})$ & $\mathrm{C}^{7}$ & 140 \\
\hline $\mathrm{H}^{9}$ & $7.55(1 \mathrm{H}, \mathrm{t})\left[{ }^{3} \mathrm{~J}_{\mathrm{H} 9-\mathrm{H} 8,10}=7.72 \mathrm{~Hz}\right]$ & $\mathrm{C}^{8}$ & 121 & $\mathrm{H}^{14}$ & $7.55(2 \mathrm{H}, \mathrm{s})$ & $\mathrm{C}^{8}$ & 112 \\
\hline $\mathrm{H}^{10}$ & $7.75(1 \mathrm{H}, \mathrm{d})\left[{ }^{3} \mathrm{~J}_{\mathrm{H} 10-\mathrm{H} 9}=6.83 \mathrm{~Hz}\right]$ & $\mathrm{C}^{9}$ & 117 & $\mathrm{H}^{15}$ & $7.90(1 \mathrm{H}, \mathrm{s})$ & $\mathrm{C}^{9}$ & 109 \\
\hline $\mathrm{H}^{12}$ & $8.24(1 \mathrm{H}, \mathrm{s})$ & $\mathrm{C}^{10}$ & 123 & $\mathrm{H}^{16}, \mathrm{H}^{17}$ & $6.50(1 \mathrm{H}, \mathrm{s})$ & $\mathrm{C}^{10}$ & 117 \\
\hline \multirow[t]{2}{*}{$\mathrm{H}^{14}$} & $7.39(2 \mathrm{H}, \mathrm{s})$ & $\mathrm{C}^{11}$ & 145 & $\mathrm{H}^{18}$ & $7.75(1 \mathrm{H}, \mathrm{s})$ & $\mathrm{C}^{11}$ & 145 \\
\hline & & $\mathrm{C}^{12}$ & 130 & $\mathrm{H}^{21}$ & $6.20(2 \mathrm{H}, \mathrm{s})$ & $\mathrm{C}^{12}$ & 130 \\
\hline
\end{tabular}


Tuzda yaklaşık 13 ppm civarında beklenen Hmabsmal'a ait - $\mathrm{COOH}$ hidrojeni gözlenememiştir. Bu hidrojenin ap'deki $\mathrm{N}^{20}$ e transfer olduğu düşünülmektedir $\left(\mathrm{H}^{20}\right)$. NMR spektrumu için hazırlanan tuz çözeltisinde asidik $\mathrm{H}^{\prime}$ nin $\mathrm{H}^{1} \rightleftharpoons \mathrm{H}^{20}$ tersinir tepkimesine uğradığ 1 düşünülmektedir. $\mathrm{Bu}$ nedenle $\quad \mathrm{H}^{1} \quad$ veya $\mathrm{H}^{20} \quad$ NMR spektrumunda gözlenememiştir. Aynı tuzun katı örnek ile FT-IR spektrumu alındığında $\mathrm{H}^{20}$ 'nin varlığı belirlenmiştir. $\mathrm{Bu}$ çalışmada hazırlanan proton transfer tuzunun; ap ve Hmabsmal oranı ${ }^{1} \mathrm{H}-\mathrm{NMR}$ spektrumundaki integrasyon oranlarından yararlanarak 1:1 olarak bulunmuştur. Örnek çözeltisi üzerine $\mathrm{D}_{2} \mathrm{O}$ ilavesinden sonra çekilen ${ }^{1} \mathrm{H}-\mathrm{NMR}$ spekturumunda (Ek 5); $\mathrm{H}^{6}, \mathrm{H}^{14}$ ve $\mathrm{H}^{21}$ hidrojenleri de döteryum ile yer değiştirdikleri için gözlenememiştir.

Proton transfer tuzu (1) bileşiğinin ${ }^{13} \mathrm{C}-\mathrm{NMR}$ spekturumunda (Ek 6, Tablo 3); 164 ppm'de gözlenen pik karboksil grubu karbonuna (-C2OO-), 167 ppm'de gözlenen pik ise amit grubunun karbon atomuna $\left(\mathrm{C}^{5}\right)$ aittir. Sülfamoyil grubunun bağlı olduğu karbon $\left(-\mathrm{C}^{11} \mathrm{SO}_{2} \mathrm{NH}_{2}\right)$ piki 145 ppm'de ve $-\mathrm{NH}$ grubuna bağl1 karbon atomunun $\left(\mathrm{C}^{7}\right)$ piki ise 140 ppm'de gözlenmiştir. Aromatik bölgede bulunan diğer karbon atomlar1 $112\left(\mathrm{C}^{8}\right), 109\left(\mathrm{C}^{9}\right), 117\left(\mathrm{C}^{10}\right), 130\left(\mathrm{C}^{12}\right), 147$ $\left(\mathrm{C}^{15}\right), 138\left(\mathrm{C}^{16}\right), 121\left(\mathrm{C}^{17}\right), 123\left(\mathrm{C}^{18}\right)$ ve $159\left(\mathrm{C}^{19}\right)$ ppm'de gözlenmiştir. Alken karbon atomları sırasıyla $131\left(\mathrm{C}^{3}\right)$ ve $132\left(C^{4}\right)$ ppm'de gözlenmiştir.

\subsection{FT-IR Sonuçları}

Başlangıç maddeleri (Hmabsmal, ap), proton transfer tuzu (1) ve metal kompleks bileşiklerinin (2-4) FT-IR değerleri Tablo 4'de verilmiştir. Şekiller 4. 1-5'de önerilen yapıları destekleyen titreşim bantları mevcuttur.

Hmabsmal ve proton transfer tuzunun FT-IR spektrumunda; $3392-3155 \mathrm{~cm}^{-1}$ aralığında gelen $v(\mathrm{~N}-\mathrm{H})$ gerilmelerinden kaynaklanan şiddetli titreşim bantları mabs'de 3486, 3387, 3312 ve $3274 \mathrm{~cm}^{-1}$, Hmabsmal da 3315, 3229 ve $3205 \mathrm{~cm}^{-1}$ ve ap ise 3443 ve $3291 \mathrm{~cm}^{-1}$ de gözlenmiştir. Tuzda 2724 ve $2527 \mathrm{~cm}^{-1}$ de gözlenen zayıf titreşim bantlarının $v\left(\mathrm{~N}^{+}-\mathrm{H}\right)$ gözlenmesi önerilen yapıyı desteklemektedir (Şekil 4 . 2) [28]. Tuz ve başlangıç maddelerinin yapılarındaki aromatik $v(\mathrm{C}-\mathrm{H})$ ve/veya alken ve alifatiklik $v(\mathrm{C}-\mathrm{H})$ gerilmelerinden kaynaklanan zayıf titreşim bantları, $3095-3060 \mathrm{~cm}^{-1}$ ve $3060-2831 \mathrm{~cm}^{-1}$ aralığında ortaya çıkmaktadır. $v(\mathrm{C}=\mathrm{O})$ gerilmelerinin titreşim bantları Hmabsmal'da $1620 \mathrm{~cm}^{-1}$ (amit) ve $1688 \mathrm{~cm}^{-1}$ (asit)'de gözlenirken, tuzda $1638 \mathrm{~cm}^{-1}$ (amit) ve $1667 \mathrm{~cm}^{-1}$ (asit) gözlenmektedir. 1622-1415 $\mathrm{cm}^{-1}$ aralığındaki titreşim bantları yapilardaki $\quad v(\mathrm{C}=\mathrm{N})$ ve $\quad v(\mathrm{C}=\mathrm{C})$ gerilmelerinden kaynaklanmaktadır. Hmabsmal ve tuzda $1363-1034 \mathrm{~cm}^{-1}$ ve $1284-1145 \mathrm{~cm}^{-1}$ aralığında gözlenen titreşim bandları ise yapıdaki $v(C-O)$ ve $v(S=O)[29]$ gerilmelerinden kaynaklanmaktadır.

Tablo 4. Habsmal metal komplekslerin bazı FT-IR bantları $\left(\mathrm{cm}^{-1}\right)$

\begin{tabular}{lllllll}
\hline \multicolumn{1}{c}{ Habsmal } & ap & $\mathbf{1}$ & $\mathbf{2}$ & $\mathbf{3}$ & $\mathbf{4}$ \\
\hline$v(\mathrm{OH})$ & $2900(\mathrm{br})$ & - & - & $3484(\mathrm{br})$ & $3538(\mathrm{br})$ & $3447(\mathrm{br})$ \\
$v\left(\mathrm{NH}_{2}\right)$ & $3315(\mathrm{~m})$ & $3443(\mathrm{~m})$ & $3330(\mathrm{~m})$ & $3391(\mathrm{~m})$ & $3478(\mathrm{~m})$ & $3322(\mathrm{~m})$ \\
& $3229(\mathrm{~m})$ & $3291(\mathrm{~m})$ & $3314(\mathrm{~m})$ & $3358(\mathrm{~m})$ & $3464(\mathrm{~m})$ & $3289(\mathrm{~m})$ \\
& $3205(\mathrm{~m})$ & & $3224(\mathrm{~m})$ & $3308(\mathrm{~m})$ & $3322(\mathrm{~m})$ & $3257(\mathrm{~m})$ \\
& & & $3191(\mathrm{~m})$ & $3280(\mathrm{~m})$ & $3246(\mathrm{~m})$ & $3230(\mathrm{~m})$ \\
& & & $3133(\mathrm{~m})$ & $3225(\mathrm{~m})$ & $3184(\mathrm{~m})$ & $3197(\mathrm{~m})$ \\
$v(\mathrm{NH})^{+}$ & - & - & $2724(\mathrm{w})$ & - & - & - \\
& & & $2527(\mathrm{w})$ & & & \\
$v(\mathrm{C}-\mathrm{H})_{\text {Ar }}$ & $3095(\mathrm{w})$ & $3070(\mathrm{w})$ & $3092(\mathrm{w})$ & $3078(\mathrm{w})$ & $3072(\mathrm{w})$ & $3073(\mathrm{w})$ \\
$v(\mathrm{C}-\mathrm{H})_{\text {Alf. }}$ & $3040(\mathrm{w})$ & - & $2939(\mathrm{w})$ & $3000(\mathrm{w})$ & $2999(\mathrm{w})$ & $3013(\mathrm{w})$ \\
& $2934(\mathrm{w})$ & & $2903(\mathrm{w})$ & $2972(\mathrm{w})$ & $2907(\mathrm{w})$ & $2935(\mathrm{w})$ \\
& $2984(\mathrm{w})$ & & $2831(\mathrm{w})$ & $2944(\mathrm{w})$ & $2886(\mathrm{w})$ & $2838(\mathrm{w})$ \\
$v(\mathrm{C}=\mathrm{O})_{\text {amit }}$ & $1620(\mathrm{~s})$ & - & $1638(\mathrm{~s})$ & $1609(\mathrm{~s})$ & $1591(\mathrm{~s})$ & $1619(\mathrm{~s})$ \\
$v(\mathrm{C}=$ O) & & & $1667(\mathrm{~s})$ & $1671(\mathrm{~s})$ & $1670(\mathrm{~s})$ & $1669(\mathrm{~s})$ \\
& $1688(\mathrm{~s})$ & - & 216 & & &
\end{tabular}


CBÜ Fen Bil. Dergi., Cilt 13, Sayı 1, 2017, 1-4 s

CBU J. of Sci., Volume 13, Issue 1, 2017, p 1-4

\begin{tabular}{lllllll}
$v(\mathrm{C}=\mathrm{N})$ & $1578(\mathrm{~s})$ & $1622(\mathrm{~s})$ & $1600(\mathrm{~s})$ & $1586(\mathrm{~s})$ & $1540(\mathrm{~s})$ & $1541(\mathrm{~s})$ \\
$v(\mathrm{C}=\mathrm{C})$ & $1541(\mathrm{~s})$ & $1593(\mathrm{~s})$ & $1541(\mathrm{~s})$ & $1547(\mathrm{~s})$ & $1478(\mathrm{~s})$ & $1508(\mathrm{~s})$ \\
& $1492(\mathrm{~s})$ & $1555(\mathrm{~s})$ & $1482(\mathrm{~s})$ & $1482(\mathrm{~s})$ & $1432(\mathrm{~s})$ & $1474(\mathrm{~s})$ \\
& $1472(\mathrm{~s})$ & $1483(\mathrm{~s})$ & $1415(\mathrm{~s})$ & $1422(\mathrm{~s})$ & & $1421(\mathrm{~s})$ \\
$v(\mathrm{C}-\mathrm{O})$ & $1435(\mathrm{~s})$ & $1435(\mathrm{~s})$ & & & & \\
& - & - & $1357(\mathrm{~s})$ & $1311(\mathrm{~s})$ & $1335(\mathrm{~s})$ & $1302(\mathrm{~s})$ \\
& & & $1212(\mathrm{~s})$ & $1205(\mathrm{~s})$ & $1210(\mathrm{~s})$ & $1222(\mathrm{~s})$ \\
$v(\mathrm{~S}=\mathrm{O})$ & $1211(\mathrm{~s})$ & - & $1052(\mathrm{~s})$ & $1099(\mathrm{~s})$ & $1153(\mathrm{~s})$ & $1094(\mathrm{~s})$ \\
& $1162(\mathrm{~s})$ & & $1300(\mathrm{~s})$ & $1255(\mathrm{~s})$ & $1252(\mathrm{~s})$ & $1250(\mathrm{~s})$ \\
$v(\mathrm{M}-\mathrm{N})$ & - & - & $1145(\mathrm{~s})$ & $1154(\mathrm{~s})$ & $1182(\mathrm{~s})$ & $1147(\mathrm{~s})$ \\
$v(\mathrm{M}-\mathrm{O})$ & - & - & - & $510(\mathrm{w})$ & $586(\mathrm{w})$ & $582(\mathrm{w})$ \\
\hline
\end{tabular}

(br; yayvan, s; şiddetli, m; orta şiddetli, w; zayıf)

Metal komplekslerinin FT-IR spektrumlarında; yapıdaki su ve $(\mathrm{OH})^{-}$gruplarından kaynaklanan $v(\mathrm{O}-\mathrm{H})$ titreşimleri $3538-3447 \mathrm{~cm}^{-1^{\prime}}$ de gözlenmiştir. Tüm metal kompleksleri için $v(\mathrm{~N}-\mathrm{H})$ grubundan kaynaklanan gerilim pikleri $3478-3184 \mathrm{~cm}^{-1}$ aralığında gözlenmiştir. Tüm metal komplekslerin önerilen yapılarındaki aromatik $v(\mathrm{C}-\mathrm{H})$ ve/veya alken ve alifatik $v(\mathrm{C}-\mathrm{H})$ gerilmelerinden kaynaklanan zayıf titreşim bantları, $3078-3072 \mathrm{~cm}^{-1}$ ve $3013-2838 \mathrm{~cm}^{-1}$ aralığında ortaya çıkmaktadır. $v(\mathrm{C}=\mathrm{O})$ gerilmesinin titreşim bantları, 2 kompleksi için $1609 \mathrm{~cm}^{-1}$ (amit) ve $1671 \mathrm{~cm}^{-1}$ (asit), 3 kompleksi için $1591 \mathrm{~cm}^{-1}$ (amit) ve $1670 \mathrm{~cm}^{-1}$ (asit) ve 4 kompleksi için $1619 \mathrm{~cm}^{-1}$ (amit) ve $1669 \mathrm{~cm}^{-1}$ (asit)'dir. Tüm metal komplekslerinde; 1586$1421 \mathrm{~cm}^{-1}$ aralığında aromatik (ve alken) $v(\mathrm{C}=\mathrm{C})$ ve $v(\mathrm{C}=\mathrm{N})$ gerilmeleri, $1335-1094 \mathrm{~cm}^{-1}$ aralığında $v(\mathrm{C}-\mathrm{O})$ gerilmeleri, $\quad 1255-1147 \quad \mathrm{~cm}^{-1}$ aralığında $v(\mathrm{~S}=\mathrm{O})$ gerilmeleri [29], 474-446 $\mathrm{cm}^{-1}$ ve $586-510 \mathrm{~cm}^{-1}$ aralığında $\mathrm{M}-\mathrm{O}$ ve $\mathrm{M}-\mathrm{N}$ gerilmeleri gözlenmiştir.

\subsection{Termal Analiz Sonuçları}

Sentezlenen metal komplekslerinin (2-4) TG/DTA değerleri Tablo 5'de spektrumları Ekler 7-9'da verilmiştir.

2 kompleksinin, $\left[\mathrm{Co}(\right.$ mabsmal $\left.)(\mathrm{ap})_{2}\left(\mathrm{H}_{2} \mathrm{O}\right)(\mathrm{OH})\right]$, termal olarak dört basamakta bozunduğu görülmektedir (Ek 7). Illk olarak 30 ve $130{ }^{\circ} \mathrm{C}$ arasinda yapidan $1 \mathrm{~mol} \mathrm{su}$ ve $1 \mathrm{~mol} \mathrm{OH}$ ayrılmıştır (endotermik pik; DTG $\max =61$ ve $114{ }^{\circ} \mathrm{C}$; deneysel 6.70, teorik 6.72). Sonra 130 ve 245 ${ }^{\circ} \mathrm{C}$ arasında yapıdan $\mathrm{SO}_{2} \mathrm{NH}_{2}$ parçasının ayrıldığ 1 gözlenmektedir (endotermik pik; DTG $\max =213$ ve 231 ${ }^{\circ} \mathrm{C}$; deneysel 14.50, teorik 14.51). Daha sonra gözlenen 245 ve $460{ }^{\circ} \mathrm{C}$ arasındaki eğim yapıdan $\mathrm{C}_{16} \mathrm{H}_{17} \mathrm{~N}_{3}$ parçasının ayrılışına karşılık gelmektedir (ekzotermik pik; DTG max $=330$ ve $396{ }^{\circ} \mathrm{C}$ deneysel 45.50 , teorik 45.58). En son basamakta ise $\mathrm{C}_{4} \mathrm{H}_{2} \mathrm{~N}_{2} \mathrm{O}_{3}$ parçası, 460 ve
$900{ }^{\circ} C^{\prime}$ de yapıdan ayrılmıştır (ekzotermik pik; DTGmax $=487$ ve $506{ }^{\circ} \mathrm{C}$; deneysel 22.70 , teorik 10.69). Termal bozunma sonrası ortaya çıkan kalıntının $\mathrm{CoO}$ olduğu düşünülerek Co yüzdesi belirlenmiştir (deneysel 10.60 , teorik 10.69).

3 kompleksinin, $\left[\mathrm{Cu}_{2}(\right.$ mabsmal $\left.)(\mathrm{ap})(\mathrm{OH})_{3}\right]$, termal olarak dört basamakta bozunduğu görülmektedir (Ek 8). İlk olarak 30 ve $170{ }^{\circ} \mathrm{C}$ arasında yapıdan $3 \mathrm{~mol} \mathrm{OH}$ ayrılmıştır (endotermik pik; DTG $\max =70^{\circ} \mathrm{C}$; deneysel 9.30, teorik 9.42). Sonra 170 ve $332{ }^{\circ} \mathrm{C}$ arasinda yapıdan $\mathrm{C}_{5} \mathrm{H}_{6} \mathrm{NO}_{2} \mathrm{~S}$ parçasının ayrıldığ gözlenmektedir (ekzotermik pik; DTG $\max =217,226$ ve $322{ }^{\circ} \mathrm{C}$; deneysel 26.80, teorik 26.63). Daha sonra gözlenen 332 ve $523{ }^{\circ} \mathrm{C}$ arasındaki eğim yapıdan $\mathrm{C}_{9} \mathrm{H}_{9} \mathrm{~N}_{2}$ parçasının ayrılışına karşılık gelmektedir (ekzotermik pik; DTGmax $=433{ }^{\circ} \mathrm{C}$ deneysel 26.90, teorik 26.81). En son basamakta ise $\mathrm{CNO}_{3}$ parçası, 523 ve $900{ }^{\circ} \mathrm{C}$ 'de yapıdan ayrılmıştır (ekzotermik pik; $\mathrm{DTG}_{\max }=700{ }^{\circ} \mathrm{C}$; deneysel 13.40, teorik 13.67). Termal bozunma sonrası ortaya çıkan kalıntının $\mathrm{CuO}$ olduğu düşünülerek $\mathrm{Cu}$ yüzdesi belirlenmiştir (deneysel 23.60, teorik 23.47).

4 kompleksinin, [Cu(mabsmal $\left.)_{2}(\mathrm{ap})_{2}\right] \cdot 3 \mathrm{H}_{2} \mathrm{O}$, termal olarak üç basamakta bozunduğu görülmektedir (Ek 9). İlk olarak 30 ve $165{ }^{\circ} \mathrm{C}$ arasında yapıdan $3 \mathrm{~mol} \mathrm{su}$ ayrılmıştır (endotermik pik; DTG $\max =60^{\circ} \mathrm{C}$; deneysel 6.20, teorik 6.39). Sonra 165 ve $420{ }^{\circ} \mathrm{C}$ arasinda yapıdan $\mathrm{C}_{10} \mathrm{H}_{12} \mathrm{~N}_{2} \mathrm{O}_{4} \mathrm{~S}_{2}$ parçasının ayrıldığ 1 gözlenmektedir (ekzotermik pik; DTG $\max =187$ ve 312 ${ }^{\circ} \mathrm{C}$; deneysel 34.30, teorik 34.11). En son basamakta ise $\mathrm{C}_{20} \mathrm{H}_{19} \mathrm{~N}_{6} \mathrm{O}_{6}$ parçası 420 ve $900{ }^{\circ} \mathrm{C}^{\prime} \mathrm{de}$ yapıdan ayrılmıştır (ekzotermik pik; DTGmax $=459$ ve $671{ }^{\circ} \mathrm{C}$; deneysel 52.00, teorik 51.99). Termal bozunma sonrası ortaya çıkan kalıntının $\mathrm{CuO}$ olduğu düşünülerek $\mathrm{Cu}$ yüzdesi belirlenmiştir (deneysel 7.50, teorik 7.51). 
Tablo 5. Sentezlenen metal komplekslerinin TG/DTA Değerleri

\begin{tabular}{|c|c|c|c|c|c|}
\hline Bileşik & Sicaklık Aralığı $\left({ }^{\circ} \mathrm{C}\right)$ & $\mathrm{DTG}_{\max }\left({ }^{\circ} \mathrm{C}\right)$ & Ayrilan Grup & Deneysel (\%) & Teorik (\%) \\
\hline \multirow[t]{5}{*}{2} & $35-130$ & 61,114 & $\mathrm{H}_{2} \mathrm{O}, \mathrm{OH}$ & 6.70 & 6.72 \\
\hline & $130-245$ & 213,231 & $\mathrm{SO}_{2} \mathrm{NH}_{2}$ & 14.50 & 14.51 \\
\hline & $245-460$ & 330,396 & $\mathrm{C}_{16} \mathrm{H}_{17} \mathrm{~N}_{3}$ & 45.50 & 45.58 \\
\hline & $460-900$ & 487,506 & $\mathrm{C}_{4} \mathrm{H}_{2} \mathrm{~N}_{2} \mathrm{O}_{3}$ & 22.70 & 22.50 \\
\hline & - & - & Co & 10.60 & 10.69 \\
\hline \multirow[t]{5}{*}{3} & $35-170$ & 70 & $3 \mathrm{OH}$ & 9.30 & 9.42 \\
\hline & $170-332$ & $217,226,322$ & $\mathrm{C}_{5} \mathrm{H}_{6} \mathrm{NO}_{2} \mathrm{~S}$ & 26.80 & 26.63 \\
\hline & $332-523$ & 433 & $\mathrm{C}_{9} \mathrm{H}_{9} \mathrm{~N}_{2}$ & 26.90 & 26.81 \\
\hline & $523-900$ & 700 & $\mathrm{CNO}_{3}$ & 13.40 & 13.67 \\
\hline & - & - & $\mathrm{Cu}$ & 23.60 & 23.47 \\
\hline \multirow[t]{4}{*}{4} & $35-165$ & 60 & $3 \mathrm{H}_{2} \mathrm{O}$ & 6.20 & 6.39 \\
\hline & $165-420$ & 187,312 & $\mathrm{C}_{10} \mathrm{H}_{12} \mathrm{~N}_{2} \mathrm{O}_{4} \mathrm{~S}_{2}$ & 34.30 & 34.11 \\
\hline & $420-900$ & 459,671 & $\mathrm{C}_{20} \mathrm{H}_{19} \mathrm{~N}_{6} \mathrm{O}_{6}$ & 52.00 & 51.99 \\
\hline & - & - & $\mathrm{Cu}$ & 7.50 & 7.51 \\
\hline
\end{tabular}

\subsection{UV-Vis Sonuçları}

Başlangıç maddeleri (Hmabsmal, ap), proton transfer tuzu ve metal komplekslerinin DMSO çözücüsü içinde alınan UV-Visible absorpsiyon spektrumları ve $\varepsilon_{0}$ değerleri Tablo 6'da verilmiştir.

Başlangiç maddeleri, proton transfer tuzu ve metal komplekslerinin DMSO $\left(10^{-3} \quad M\right)$ içinde alınan spektrumlarında $\pi \rightarrow \pi^{*}$ elektronik geçişleri Hmabsmal için $290 \mathrm{~nm}$; ap için 327 ve $303 \mathrm{~nm}$; 1 için 318 ve 309 nm; 2 kompleksi için 292 nm; 3 kompleksi için 303 ve $283 \mathrm{~nm}$ ve 4 kompleksi için $289 \mathrm{~nm}$ olarak gözlenmiştir. Komplekslerdeki metal iyonunun $\mathrm{d} \rightarrow \mathrm{d}$ elektronik geçişleri, 2 kompleksi için 779 nm; 3 kompleksi için $760 \mathrm{~nm}$ ve 4 kompleksi için $760 \mathrm{~nm}$ olarak gözlenmiştir.

Çalışılan tüm bileşiklerin UV-Vis spektrumları incelendiğinde, $\mathrm{n} \rightarrow \pi^{*}$ elektronik geçişlerine rastlanmamıştır. $\mathrm{Bu}$ geçişlerin, şiddetli $\pi \rightarrow \pi^{*}$ geçişlerinin altında kaldığı düşünülmektedir. Ayrıca $\pi \rightarrow \pi^{*}$ ve $\mathrm{d} \rightarrow \mathrm{d}$ geçiş şiddetlerinin $\left(\varepsilon_{0}\right)$ beklenen değerler aralığında olduğu gözlenmiştir.

Tablo 6. Sentezlenen bileşiklerin DMSO içindeki UV spektrumları $\left(\mathrm{nm}\left(\varepsilon_{0}\right)\right)$

\begin{tabular}{llllll}
\hline Habsmal & ap & $\mathbf{1}$ & $\mathbf{2}$ & $\mathbf{3}$ & $\mathbf{4}$ \\
\hline $290(24510)$ & $327(43400)$ & $318(43400)$ & $292(14300)$ & $303(25100)$ & $289(13100)$ \\
& $303(43400)$ & $308(39720)$ & $779(90)$ & $\begin{array}{l}283(48000) \\
760(20)\end{array}$ & $760(20)$ \\
\hline
\end{tabular}

\subsection{Manyetik Duyarlılık Sonuçları ve Molar İletkenlik Sonuçları}

Sentezlenen metal komplekslerinin deneysel ve teorik manyetik duyarlılık sonuçlarında deneysel olarak elde edilen değerler ile teorik değerler Şekiller 4. 2-5'de önerilen yapıların uyum içerisinde olduğu gözlenmiştir.

2 kompleksi manyetik duyarlılığı deneysel olarak sırasıyla 3.80 BM bulunmuştur. Bu değer komplekste üç eşleşmemiş elektron sayısını işaret eder. Buradan $\mathrm{Co}(\mathrm{II})$ iyonunun $\mathrm{d}^{7}$ elektronik dağılımına sahip olduğu söylenebilir. Sentezlenen diğer komplekslerde ise manyetik duyarlılığ 1 deneysel olarak 1.69 (3) ve 1.65 (4) BM bulunmuştur. Bu değerler komplekslerde bir eşleşmemiş elektron sayısını işaret eder. Buradan bu komplekslerde $\mathrm{Cu}(\mathrm{II})$ iyonunun $\mathrm{d}^{9}$ elektronik dağılımına sahip olduğu söylenebilir. Bunlar Şekiller 4. 3-5'de önerilen yapıları desteklemektedir. 
CBÜ Fen Bil. Dergi., Cilt 13, Sayı 1, 2017, 1-4 s

DMSO çözücüsü içinde $\left(10^{-3} \mathrm{M}\right)$ yapılan iletkenlik ölçümleri sonucunda bütün komplekslerin iletkenlikleri sırasıyla 15.5, 8.8 ve $9.9 \mu \mathrm{S} / \mathrm{cm}$ aralığında gözlenmiştir. $\mathrm{Bu}$ sonuçlar kompleks yapılarının beklendiği gibi iyonik olmadığını göstermektedir [30] ve buda Şekiller 4. 3-5'de önerilen yapıları desteklemektedir.

\subsection{In vitro İnhibisyon Çalışmalarının Sonuçları}

Tablo 7'de verilen inhibisyon değerleri incelendiğinde sentezlenen bileşiklerin tamaminın hCA I ve hCA II izoenzimlerinin esteraz aktivitesini inhibe ettikleri, hidrataz aktivitesi üzerinde ise sadece 3 bileşiğinin inhibisyon etkisi gösterdiği görülmektedir. Hidrataz aktivitesinin inhibisyonu için $-\mathrm{SO}_{2} \mathrm{NH}_{2}$ grubunun enzimin aktif bölgesindeki $\mathrm{Zn}^{2+}$ iyonuna bağlanması gerektiği düşünüldüğünde sentezlenen bileşiklerden bazılarının $\mathrm{Zn}^{2+}$ iyonuna bağlandığı, bazılarının ise bağlanmadığ 1 tahmini yürütülebilir. Hidrataz aktivitesinin inhibisyonu için kıyaslama yapıldığında 3 bileşiğinin referans bileşik olan asetazolamit (AAZ) den daha zayıf inhibisyon potansiyeline sahip olduğu görülmektedir. Bileşiğin hCA II hidrataz aktivitesi üzerindeki inhibisyon etkisinin hCA I üzerindeki inhibisyon etkisinden daha kuvvetli olduğu tespit edilmiştir.

Esteraz aktivitesinin inhibisyonu için kıyaslama yapıldığında ise tüm bileşiklerin AAZ'den daha zayıf
CBU J. of Sci., Volume 13, Issue 1, 2017, p 1-4

inhibisyon etkisine sahip oldukları görülmüştür. Ancak sentezlenen bileşikler arasında 2 ve 3 bileşikleri AAZ ile daha kıyaslanabilir büyüklükte inhibisyon etkisine sahiptirler. Ayrica sentezlenen metal komplekslerinin, başlangıç maddesi (Hmabsmal) ve proton transfer tuzundan (1) daha kuvvetli inhibisyon etkileri vardır. Metal kompleksleri arasında 4 bileşiği izoenzimler üzerinde en zayıf inhibisyon etkisine sahiptir. Genel olarak inhibisyon potansiyellerindeki bu farklılıkların bileşiklerin yapılarında bulunan atom veya grupların enzimin aktif bölgesindeki amino asitler ile farklı şekilde etkileşime girmesi sonucu oluştuğu düşünülmektedir. Buradan hareketle 2 ve 3 bileşiklerinin, diğer bileşiklere nazaran enzimin aktif bölgesi ile daha iyi etkileşime girdiği söylenebilir. Ancak bu verilerin doğrulanması için enzim-inhibitör komleksinin X-1şınları kırınımı yöntemi ile analiz edilmesi gereklidir. $\mathrm{Bu}$ tarz analizler ve protein yapılarının çözümlenmesi ise ülkemizde henüz yapılamamaktadır. Esteraz $K_{\mathrm{i}}$ çalışmalarında ise bileşiklerin yarışmasız inhibisyon gösterdikleri tespit edilmiştir.

Bileşiklerin inhibisyon potansiyellerinin güçlü olması in vivo çalışmalarda da kullanılabilmesinin kapısını açmaktadır. Sentezlenen bileşikler bu çalışmalarda denenerek glokom tedavisi için daha detaylı analiz edilmiş olacaklardır.

Tablo 7. Sentezlenen bileşiklerin insan eritrosit karbonik anhidraz izoenzimleri (hCA I ve hCA II) üzerine in vitro şartlarda etkisi

\begin{tabular}{|c|c|c|c|c|c|c|}
\hline \multirow[t]{2}{*}{ Bileşik } & \multicolumn{2}{|c|}{ Hidrataz $\mathrm{IC}_{50^{\mathrm{a}, \mathrm{b}}}(\mu \mathrm{M})$} & \multicolumn{2}{|c|}{ Esteraz $\mathrm{IC}_{50^{\mathrm{a}}} \mathrm{b}(\mu \mathrm{M})$} & \multicolumn{2}{|l|}{$K_{\mathrm{i}}^{\mathrm{a}, \mathrm{b}}(\mu \mathrm{M})$} \\
\hline & hCA I & hCA II & hCA I & hCA II & hCA I & hCA II \\
\hline AAZ & $0.39 \pm 0.008$ & $0.20 \pm 0.005$ & $0.42 \pm 0.004$ & $0.31 \pm 0.008$ & $0.26 \pm 0.003$ & $0.14 \pm 0.005$ \\
\hline ap & - & - & - & - & - & - \\
\hline 1 & - & - & $6.91 \pm 0.16$ & $5.36 \pm 0.10$ & $3.45 \pm 0.11$ & $2.56 \pm 0.04$ \\
\hline 2 & - & - & $1.73 \pm 0.08$ & $1.46 \pm 0.15$ & $1.12 \pm 0.11$ & $0.84 \pm 0.06$ \\
\hline 4 & - & - & $5.46 \pm 0.16$ & $5.01 \pm 0.17$ & $2.37 \pm 0.11$ & $1.66 \pm 0.12$ \\
\hline
\end{tabular}

\section{Sonuçlar}

$\mathrm{Bu}$ proje çalışmasında, 3-aminobenzensulfonamit (mabs) ile maleik anhidrit (mal) bileşiğinin tepkimesi sonucunda sulfomoil grubu içeren amit bileşikler sentezlenmiştir [(E)-4-okso-4-(3sülfamoyilfenil) amino)büt-2-enoik asit, Hmabsmal]. Hmabsmal ile 2-aminopiridin (ap) tepkimesinden yeni proton transfer tuzu bileşiği 
$\left[(\mathrm{Hap})^{+}(\right.$mabsmal)-, 2-aminopridinyum (E)-4-okso-4(3-sülfamoyilfenilamino) büt-2-enoat,

hazırlanmıştır. Çalışmada iki yöntemle metal kompleksleri sentezlenmiştir. Birinci yöntemde tuzun $\mathrm{Co}(\mathrm{II}) \quad$ (2) ve $\mathrm{Cu}(\mathrm{II}) \quad$ (3) ile verdiği komplekslerin yapıları sentezlenmiştir. İkinci yöntemde ise tuz için kullanılan sarf malzemelerin tuz oluşumu olayı gerçekleşmeden karışım olarak birbirine ilave edilmesi ile $\mathrm{Co}(\mathrm{II})$ (2) ve $\mathrm{Cu}$ (II) (4) verdiği komplekslerin yapıları elde edilmiştir. Her iki yöntemde de $\mathrm{Co}$ (II) ile tepkimelerden ayn ürün elde edilmiştir (2). Proton transfer tuzu ve geçiş metal komplekslerinin tamamı amorf halde elde edilmiştir. Proton transfer tuzunun yapısı elementel analiz, ${ }^{1} \mathrm{H}-\mathrm{NMR},{ }^{13} \mathrm{C}-\mathrm{NMR}$, IR ve UV-Vis metotları ile geçiş metal komplekslerinin yapıları ise, elementel analiz, ICP-OES, FT-IR, UV-Vis, termal analiz, manyetik duyarlılık, molar iletkenlik, yük denkliği ve daha önceki çalışmalar ile önerilmiştir.

Sentezlenen tüm maddeler DMSO, DMF gibi polar çözücülerde çözünmektedir.

Sentezlenen başlangıç maddesi ve proton transfer tuzunun DMSO içerisinde alınan ${ }^{1} \mathrm{H}-\mathrm{NMR}$ ve ${ }^{13} \mathrm{C}$ NMR spektrumları incelenerek, protonlarından kaynaklanan kimyasal kayma değerleri ile yapıları açıklanmıştır. Bu çalışmada hazırlanan tuzun asit (Hmabsmal) ve baz (ap) oranı NMR sonuçlarına göre belirlenmiştir. Buna göre hazırlanan proton transfer tuzundaki asit-baz birleşme oranları 1:1 olarak bulunmuştur.

$\mathrm{Bu}$ çalışmada sentezlenen Hmabsmal bileşiği ve tuzun IR spektrumlarına bakıldığında $v(\mathrm{~N}-\mathrm{H})$ gerilmelerinden kaynaklanan pikler gözlenmiştir. Tuzda $v\left(\mathrm{~N}^{+}-\mathrm{H}\right)$ titreşim bandının gözlenmesi önerilen yapıyı desteklemektedir. Metal komplekslerinde, tuzda gözlenen $v\left(\mathrm{~N}^{+}-\mathrm{H}\right)$ pikleri gözlenmemiştir. Bunun sonucunda kompleks bileşiklerin yapısında, tuzun yapımında kullanılan asit veya bazın tamamlayıcı iyon şeklinde bulunmadığı anlaşılmaktadır. Ayrıca iletkenlik ölçümleri de bu önerilen yapıları desteklemektedir.

Başlangıç maddesi, proton transfer tuzları ve metal komplekslerinin DMSO-d6 içerisinde alınan UVVisible spektrumları ile $\pi \rightarrow \pi^{*}$ elektronik geçişleri ve metal komplekslerdeki metal iyonlarının $d \rightarrow d$ geçişlerinin dalga boyları belirlenmiş ve bu geçişler عo değerleri ile desteklenmiştir.

Metal komplekslerinin manyetik duyarlılık çalışmalarında; metal iyonlarının kobalt kompleksinde $\mathrm{Co}(\mathrm{II})\left(\mathrm{d}^{7}\right)$ şeklinde kaldığ 1 ve üç tane eşleşmemiş elektron taşıdığı, bakır komplekslerinde $\mathrm{Cu}(\mathrm{II})\left(\mathrm{d}^{9}\right)$ şeklinde kaldığ 1 ve bir tane eşleşmemiş elektron taşıdığ1 gözlenmiştir. Bu sonuçlar diğer spektroskopik analizler ile uyum içerisindedir.

İletkenlik ölçümleri sonucunda bütün komplekslerin iyonik olmadığ bulunmuştur. Bu da önerilen yapıları desteklemektedir.

In vitro çalışmalar sonucunda yeni sentezlenen bileşiklerin karbonik anhidraz izoenzimleri olan hCA I ve hCA II üzerinde inhibisyon etksine sahip olduğu gözlenmiştir. Buradan hareketle bu bileşiklerin daha ileri çalışmalar olan in vivo çalışmalarda kullanılabileceğini söyleyebiliriz.

$\mathrm{Bu}$ çalışmada sentezlenen başlangıç maddesi (Hmabsmal), proton transfer tuzu ve metal komplekslerinin yapıları Şekiller 4. 1-5'de sırasıyla verilmiştir. $\mathrm{Bu}$ yapıların önerilmesinde, yukarıda tartışılan deneysel sonuçlar, yük denkliği ve daha önce yapılmış benzer çalışmalar dikkate alınmıştır [11,26,31-35].

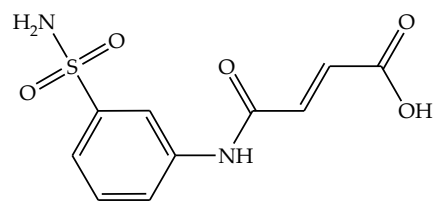

Şekil 4. 1 Hmabsmal bileşiğinin yapısı

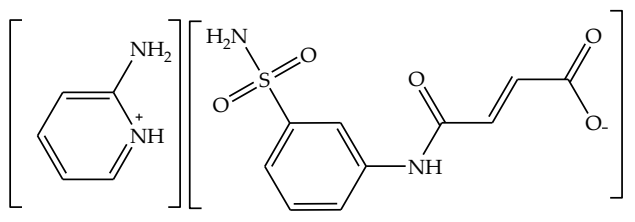

Şekil 4. 2 (1) bileşiğinin yapısı

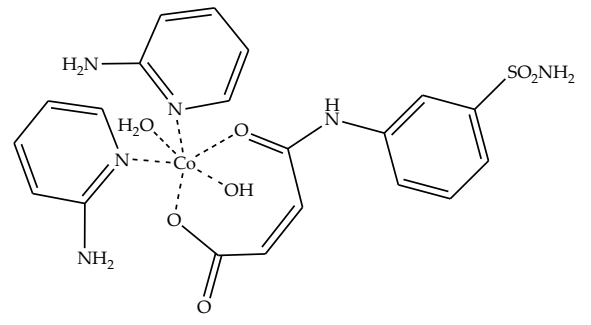

Şekil 4.3 (2) bileşiğinin yapısı 


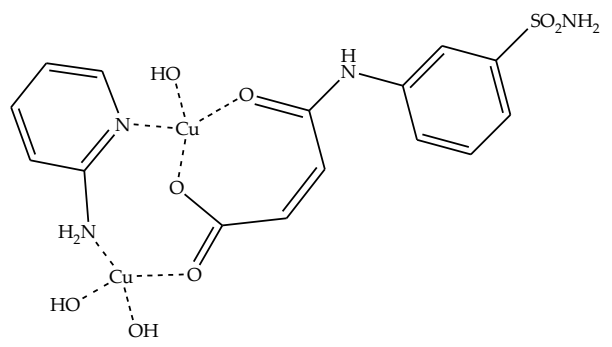

Şekil 4.4 (3) bileşiğinin yapısı

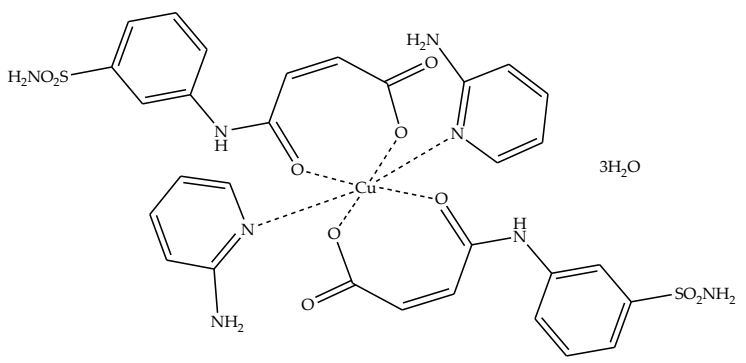

Şekil 4.5 (4) bileşiğinin yapısı

\section{Teşekkür}

$\mathrm{Bu}$ çalışmaya katkılarından dolayı Dumlupınar Üniversitesi Bilimsel Araştırma Projeleri Komisyonu'na teşekkür ederiz (Proje No: 2013/36).

\section{Referanslar}

[1] Macdonald, J.C.; Dorrestein, P.C.; Pilley, M.M.; Foote, M.M.; Lundburg, J.L.; Henning, R.W.; Schultz, A.J.; Manson, J.L. Design of layered crystalline materials using coordination chemistry and hydrogen bonds. Journal of the American Chemical Society. 2000; 122, 11692-11702.

[2] Aghabozorg, H.; Manteghi, F.; Sheshmani, S. A brief review on structural concepts of novel supramolecular proton transfer compounds and their metal complexes. Journal of the Iranian Chemical Society. 2008; 5(2), 184-227.

[3] Supuran, C.T. Carbonic anhydrases: novel therapeutic applications for inhibitors and activators. Nature Reviews Drug Discovery. 2008; 7 , 168-181.

[4] Netland, P.A. Glaucoma medical therapy. Oxford University Press Inc. 2008; 290.

[5] Allen, R.G.; Pereira, L.S. Raes D.; Smith, M. Crop evapotranspiration: Guidelines for computing crop water requirements. Irr and Drain, UN-FAO, Rome, Italy $1998 ; 56$.

[6] Prescott, J.J.; Baggot, D.J. Antimicrobial therapy in veterinary medicine. International Book Distributing Co.; India, 1993; 564-565.

[7] Bywater, R.J. Sulfonamides and diaminopyrimidines. In: Veterinary Applied Pharmacology and Therapeutics. Eds: Brander, G.C.; Pugh, D.M.; Bywater, R.J.; Jenkins, W.L. 5 th Ed, Baillere Tindali, London, 1991; 489-494.

[8] Supuran, C.T.; Briganti, F.; Tilli, S.; Chegwidden, W.R.; Scozzafava, A. Carbonic Anhidrase Inhibitors: Sulfonamide as Antitumor Agents. Bioorganic \& Medicinal Chemistry. 2000; 9, 703-714.

[9] Yenikaya, C.; Sarı, M.; Bülbül, M.; Ilkimen, H.; Çelik, H.; Büyükgüngör, $O$. Synthesis, characterization and antiglaucoma activity of a novel proton transfer compound and a mixedligand $\mathrm{Zn}(\mathrm{II})$ complex. Bioorganic \& Medicinal Chemistry. 2010; 18(2), 930-938.

[10] Yenikaya, C.; Sarı, M.; Bülbül, M.; Ilkimen, H.; Çınar, B.; Büyükgüngör, O. Synthesis and characterization of two novel proton transfer compounds and their inhibition studies on Carbonic Anhydrase isoenzymes. Journal of Enzyme Inhibition and Medicinal Chemistry. 2011; 26(1), 104-114.

[11] Yenikaya, C.; Ilkimen, H.; Demirel, M.M.; Ceyhan, B.; Tunca E.; Bülbül, M.; 2-Aminopiridin ile (E)-4Okso-4-((4-sülfamoyilfenil)amino)büt-2-enoik

Asitin Proton Transfer Tuzunun Sentezi, Metal Komplekslerinin Hazırlanması ve İnhibisyon Özelliklerinin İncelenmesi. Afyon Kocatepe Üniversitesi Fen ve Mühendislik Bilimleri Dergisi 2016; 16, 41-53,

[12] Yenikaya, C.; Ilkimen, H.; Demirel, M.M.; Ceyhan, B.; Bülbül, M.; Tunca E. Preparation of Two Maleic Acid Sulfonamide Salts And Their $\mathrm{Cu}$ (II) Complexes and Antiglaucoma Activity Studies. Journal of the Brazilian Chemical Society. 2016; 27(10), 1706-1714.

[13] Kempte, R.; Brenner, S.; Arndt, P. Mononuclear Tris(aminopyridinato)zirconium Alkyl, Aryl, and Alkynyl Complexes. Organometallics 1996; 15, 1071-1074.

[14] Fuhrmann, H.; Brenner, S.; Arndt P.; Kempe, R. Octahedral Group 4 Metal Complexes That Contain Amine, Amido, and Aminopyridinato Ligands: Synthesis, Structure, and Application in $\alpha$-Olefin 
Oligo- and Polymerization. Inorganic Chemistry. $1996 ; 35,6742-6745$.

[15] Téllez, F.; López-Sandoval, H.; Castillo-Blum, S.E; Barba-Behrens, N. Coordination behavior of benzimidazole, 2-substituted benzimidazoles and benzothiazoles, towards transition metal ions. Arkivoc (v). 2008; 245-275.

[16] Yenikaya, C.; Poyraz, M.; Sarı, M.; Demirci, F.; İlkimen, H.; Büyükgüngör, O. Synthesis, characterization and biological evaluation of a novel $\mathrm{Cu}(\mathrm{II})$ complex with the mixed ligands 2,6pyridinedicarboxylicacid and 2-aminopyridine. Polyhedron 2009; 28(16), 3526-3532.

[17] Mistri, S.; Zangrando, E.; Manna, S.C. Cu(II) complexes of pyridine-2,6-dicarboxylate and $\mathrm{N}$ donor neutral ligands: Synthesis, crystal structure, thermal behavior, DFT calculation and effect of aromatic compounds on their fluorescence. Inorganica Chimica Acta. 2013; 405, 331-338.

[18] Lah, N.; Giester, J.; Segedin, P. and Leban, I.; 2001. Copper(II) carboxylates with 2-aminopyridine. Synthesis, characterization and a study of the dimer-monomer equilibrium in acetonitrile solutions by VIS-spectroscopic and microcalorimetric titrations. New Journal of Chemistry. 25, 753-759.

[19] Mei, L.; Ming, T.H.; Rong, L.Q.; Jie, S.; Zhong, Y.S.; Liang, L.X. The synthesis of N-Zn, N-Cu complexes involving 2-amino pyridine and ethylenediamine ligands and application to the Henry reaction. Journal of Chemical Sciences. 2009; 121(4), 435-440.

[20] Poddar, R.K.; Agarwala, U. Reactions of $\mathrm{Ru}\left(\mathrm{PPh}_{3}\right)_{2} \mathrm{Cl}_{2}$ and $\left[\mathrm{Ru}\left(\mathrm{AsPh}_{3}\right)_{2} \mathrm{Cl}_{2}\right]_{2}$ with various donor molecules. Journal of Inorganic and Nuclear Chemistry. 1973; 35, 3769-3779.

[21] Raso, A.G.; Fiol, J.J.; Zafra, A.L.; Cabrero, A.; Mata, I.; Molins, E. Crystal structures of the Nsalicylidene-L-serinatoaquacopper(II) monohydrate and its ternary derivative with 2-aminopyridine. Polyhedron 1999; 18, 871-878.

[22] Kremlev, M.M.; Kul'chitskaya, N.E.; Biba, A.D.; Romanenko, V.D. Arenesulfonamides. XXVII. N(sulfamoylaryl)maleimides. Khimicheskaya Tekhnologiya (Kharkov). 1971; 21, 5-10.

[23] Innocenti, A.; Scozzafava, A.; Parkkila, S.; Pucceti, L.; De Simone, G.; Supuran, C.T. Investigations of the esterase, phosphatase, and sulfatase activities of the cytosolic mammalian carbonic anhydrase isoforms I, II, and XIII with 4-nitrophenyl esters as substrates. Bioorganic $\mathcal{E}$ Medicinal Chemistry Letters. 2008; 18, 2267-2271.

[24] Verpoorte, J.A.; Mehta, S.; Edsall, J.T. Esterase activities of human carbonic anhydrases B and C. Journal of Biological Chemistry. 1967; 242, 42214229.

[25] Ciftci, M.; Bulbul, M.; Gul, M.; Gumuştekin, K.; Dane, Ş.; Suleyman, H. Effects of nicotine and Vitamin E on carbonic anhydrase activity in some rat tissues in vivo and in vitro. Journal of Enzyme Inhibition and Medicinal Chemistry. 2005; 20, 103109.

[26] Bulbul, M.; Hisar, O.; Beydemir, S.; Ciftci, M.; Kufrevioğlu, O.I. The in vitro and in vivo inhibitory effects of some sulfonamide derivatives on rainbow trout (Oncorhynchus mykiss) erythrocyte carbonic anhydrase activity. Journal of Enzyme Inhibition and Medicinal Chemistry. 2003; 18, 371-375.

[27] Williams, D. H., Fleming, I. Spectroscopic Methods in Organic Chemistry. 4th ed. revised, McGraw-Hill Book Company (UK) Limited, 1989.

[28] Cook D. Vibrational spectra of pyridinium salts. Canadian Journal of Chemistry, 1961; 39, 2009-24.

[29] Gowda, B.T.; Jyothi, K.; Souza, J.D.D.Z. Infrared and NMR spectra of arylsulphonamides, 4-X$\mathrm{C}_{6} \mathrm{H}_{4} \mathrm{SO}_{2} \mathrm{NH}_{2}$ and $\mathrm{i}-\mathrm{X}, \mathrm{j}-\mathrm{YC}_{6} \mathrm{H}_{3} \mathrm{SO}_{2} \mathrm{NH}_{2}\left(\mathrm{X}=\mathrm{H}\right.$; $\mathrm{CH}_{3}$; $\mathrm{C}_{2} \mathrm{H}_{5} ; \mathrm{F} ; \mathrm{Cl}$; Br; I or $\mathrm{NO}_{2}$ and $\mathrm{i}-\mathrm{X}, \mathrm{j}-\mathrm{Y}=2,3-\left(\mathrm{CH}_{3}\right)(2)$; 2,4-( $\left.\mathrm{CH}_{3}\right)(2) ; 2,5\left(\mathrm{CH}_{3}\right)(2) ; 2-\mathrm{CH}_{3}, 4-\mathrm{Cl}_{2}$ 2- $\mathrm{CH}_{3}, 5-\mathrm{Cl} ; 3-$ $\mathrm{CH}_{3}, 4-\mathrm{Cl} ; 2,4-\mathrm{Cl}-2$ or 3,4-Cl-2). Naturforsch. 2002; $57 a, 967$.

[30] Geary, W.J. The use of conductivity measurements in organic solvents for the characterisation of coordination compounds, Coordination Chemistry Reviews. 1971; 7(1), 81-122.

[31] Ceyhan, B. 2-Hidrojenbenzimidazol ile 4-okso-4-((4sülfomoilfenil)amino)büt-2-enoik asit tuzunun sentezi, geçiş metal komplekslerinin hazırlanması ve kullanım alanlarının araştırılması. Yüksek Lisans Tezi, Dumlupınar Üniversitesi Fen Bilimleri Enstitüsü, 2013.

[32] Demirel, M.M. 2-Aminopiridin ile 4-okso-4-((4sülfomoilfenil)amino)büt-2-enoik asit tuzunun sentezi, geçiş metal komplekslerinin hazırlanması ve kullanım alanlarının araştırılması. Yüksek Lisans Tezi, Dumlupınar Üniversitesi Fen Bilimleri Enstitüsü, 2013. 
[33] Shah, A.I.; Shukla, H.M.; Shah, P.J.; Raj, D.S., Novel co-ordination polymers of 8-hydroxyquinoline. Elixir Chemical Physics. 2012; 44, 7378-7381.

[34] Lazarou, K.N.; Perlepes, S.P.; Psycharis, V.; Raptopoulou, C.P. Synthetic study of the ternary copper(II)/maleamate(-1)/1,10-phenanthroline reaction system: Mononuclear, dinuclear and polymeric complexes. Polyhedron. 2008; 27, 21312142.

[35] Ashok, M.; Prasad, A.V.S.S.; Ravinder, V. Synthesis, Spectral Studies and Catalytic Activity of Ruthenium(II) Complexes with Organic Amide Ligands. Journal of the Brazilian Chemical Society. 2007; 18(8), 1492-1499. 
CBÜ Fen Bil. Dergi., Cilt 13, Sayı 1, 2017, 1-4 s

\section{Ekler}

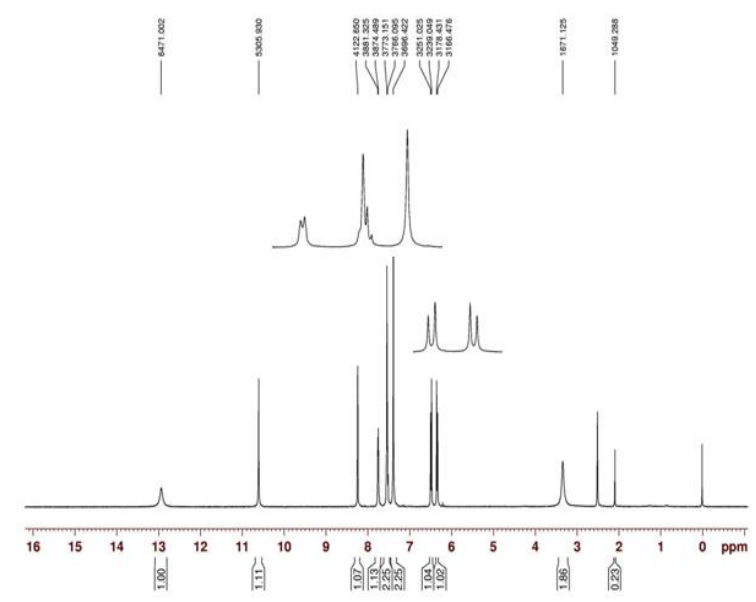

EK 1. Hmabsmal bileşiğinin ${ }^{1} \mathrm{H}-\mathrm{NMR}$ spektrumu

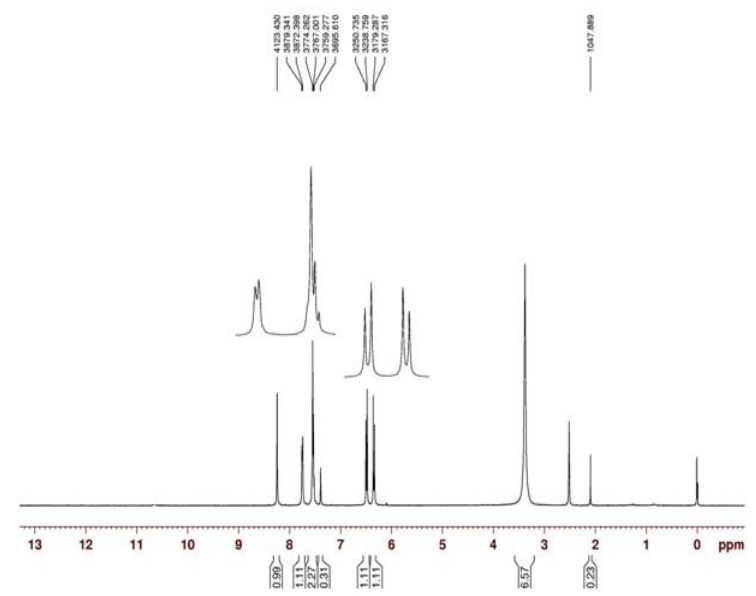

EK 2. Hmabsmal bileşiğinin $\mathrm{D}_{2} \mathrm{O}$ ilaveli ${ }^{1} \mathrm{H}-\mathrm{NMR}$ spektrumu

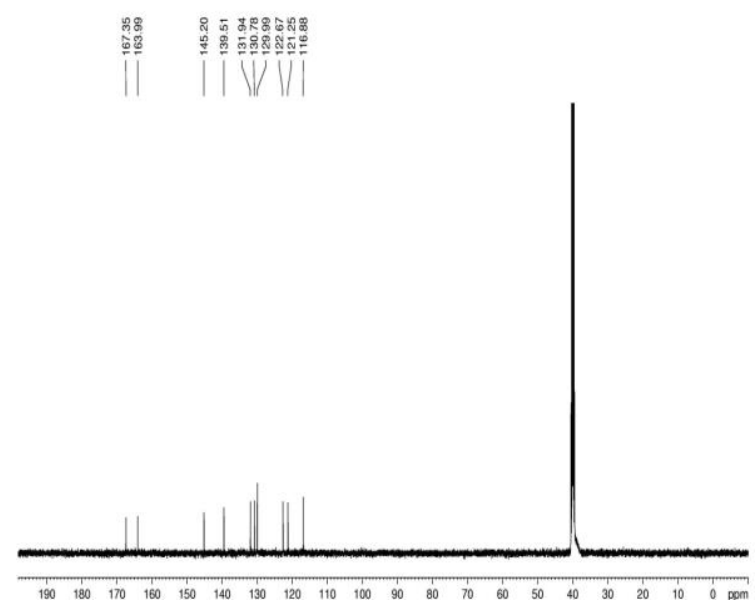

EK 3. Hmabsmal bileşiğinin ${ }^{13} \mathrm{C}-\mathrm{NMR}$ spektrumu
CBU J. of Sci., Volume 13, Issue 1, 2017, p 1-4

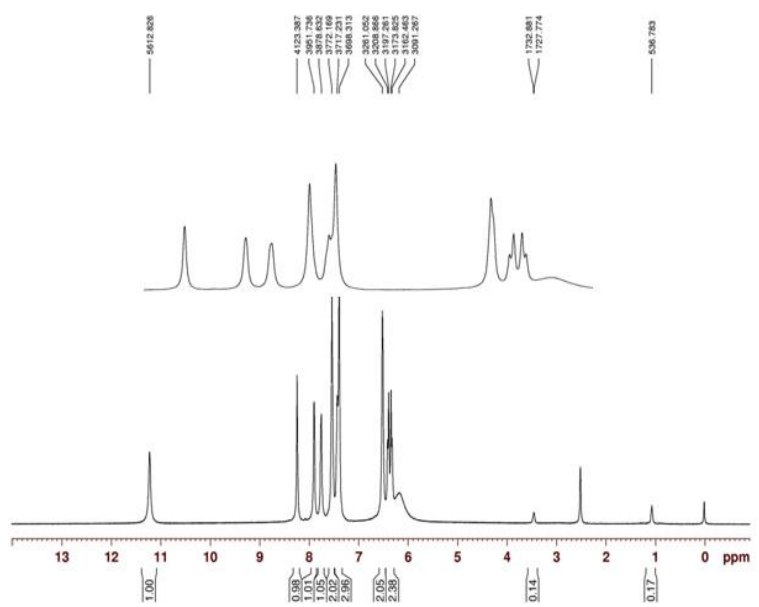

EK 4. (1) bileşiğinin ${ }^{1} \mathrm{H}-\mathrm{NMR}$ spektrumu

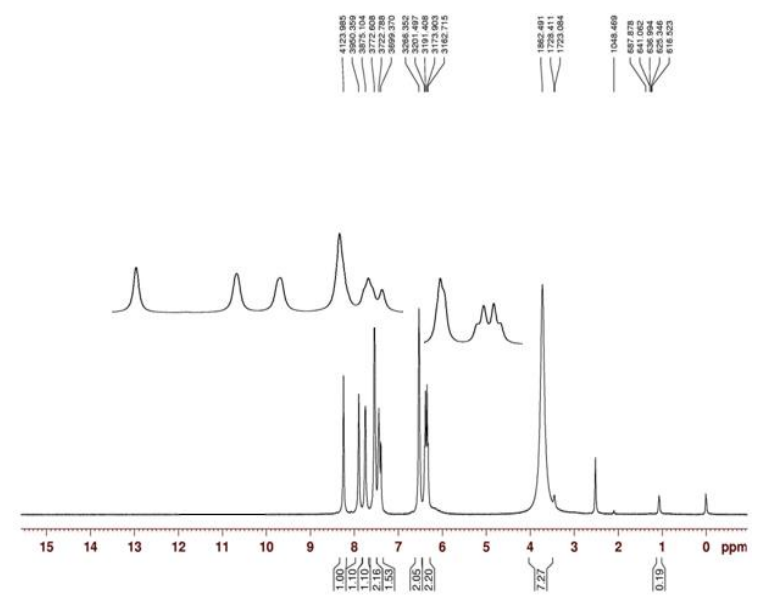

EK 5. (1) bileşiğinin $\mathrm{D}_{2} \mathrm{O}$ ilaveli ${ }^{1} \mathrm{H}-\mathrm{NMR}$ spektrumu

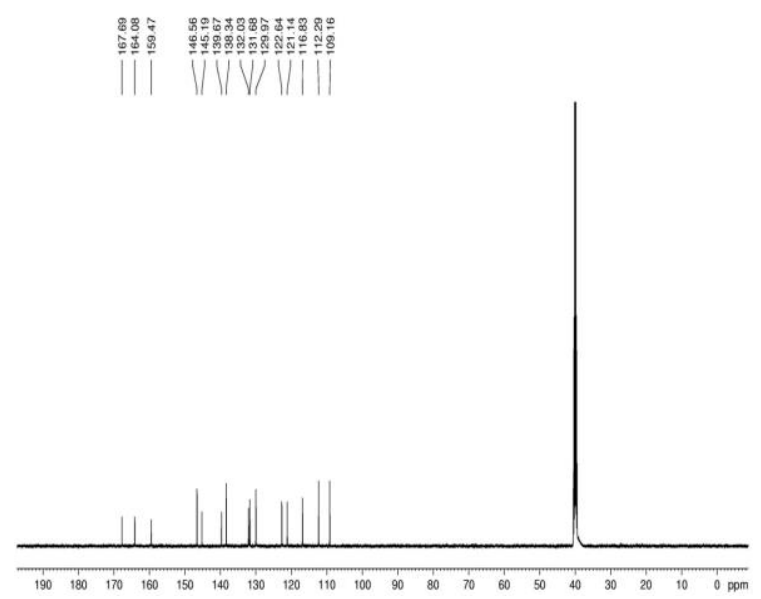

EK 6. (1) bileşiğinin ${ }^{13} \mathrm{C}-\mathrm{NMR}$ spektrumu 
CBÜ Fen Bil. Dergi., Cilt 13, Sayı 1, 2017, 1-4 s

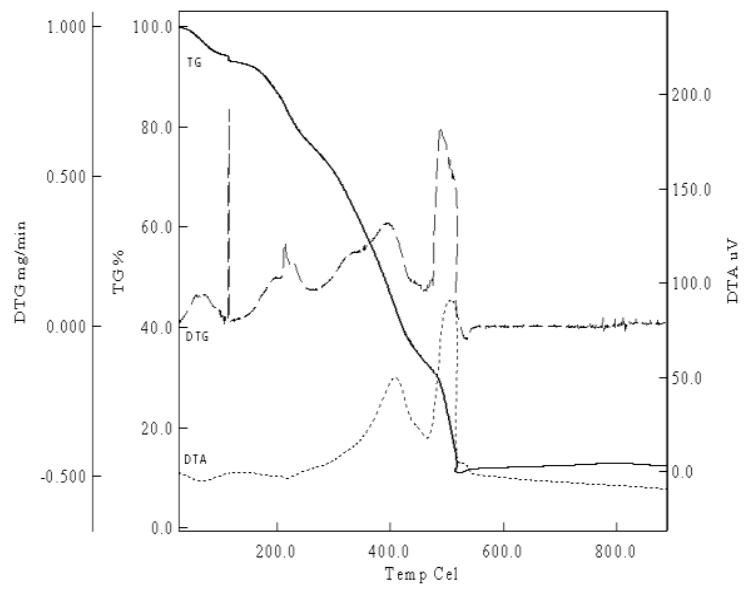

EK 7. (2) kompleksinin TG/DTA spektrumu

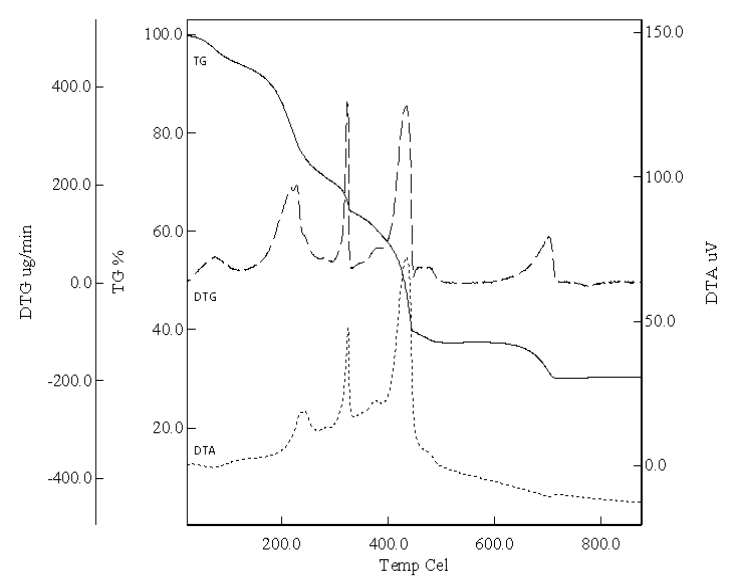

CBU J. of Sci., Volume 13, Issue 1, 2017, p 1-4

EK 8. (3) kompleksinin TG/DTA spektrumu

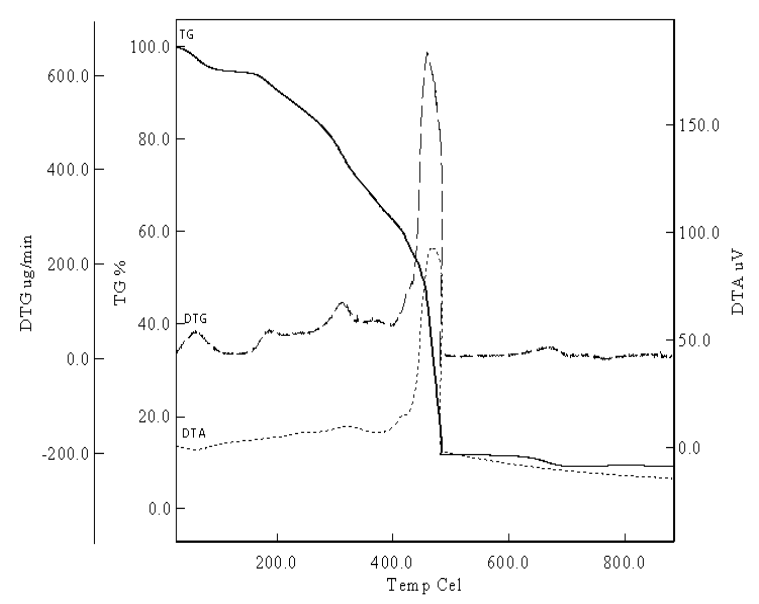

EK 9. (4) kompleksinin TG/DTA spektrumu 